\title{
STRUCTURAL AND ELECTRICAL PROPERTIES OF BERYLLIUM IMPLANTED SILICON CARBIDE
}

\author{
T. HENKEL*, Y. TANAKA*, N. KOBAYASHI*, H. TANOUE*, \\ M. GONG**, X.D. CHEN**, S. FUNG** and C.D. BELING** \\ * Electrotechnical Laboratory, Tsukuba, Ibaraki 305-8568, Japan, henkel@etl.go.jp \\ ** Physics Department, The University of Hong Kong, Hong Kong, China
}

\section{ABSTRACT}

Structural and electrical properties of beryllium implanted silicon carbide have been investigated by secondary ion mass spectrometry, Rutherford backscattering as well as deep level transient spectroscopy, resistivity and Hall measurements. Strong redistributions of the beryllium profiles have been found after a short post-implantation anneal cycle at temperatures between $1500{ }^{\circ} \mathrm{C}$ and $1700^{\circ} \mathrm{C}$. In particular, diffusion towards the surface has been observed which caused severe depletion of beryllium in the surface region. The crystalline state of the implanted material is well recovered already after annealing at $1450{ }^{\circ} \mathrm{C}$. However, four deep levels induced by the implantation process have been detected by deep level transient spectroscopy.

\section{INTRODUCTION}

Silicon carbide (SiC) is a promising material for high temperature, high frequency, and high power device applications. Group III elements are commonly used as acceptor dopants for this semiconductor. Investigations on $p$-type $\mathrm{SiC}$ doped with these elements, however, revealed poor electrical characteristics due to high acceptor ionization energies and low hole mobilities [1-5]. Therefore, alternative dopants with a higher electrical activation are highly desirable.

Due to the low mass and high solubility in the $\mathrm{SiC}$ lattice [6], beryllium (Be) can be used for the production of thick $p$-type layers applying ion implantation. However, there have been very few reports on Be doped $\mathrm{SiC}$ [7-12]. Be is known to be an electrically active impurity, i.e., a doubly charged acceptor in $\mathrm{SiC}$ [10]. Two acceptor levels at 0.42 and $0.6 \mathrm{eV}$, respectively, were determined by Hall measurements [8]. Further, one deep level at $0.38 \mathrm{eV}$ was obtained by $\mathrm{I}-\mathrm{V}$ measurements on $p-n$ junctions produced by Be implantation [12]. However, the precision of these results is questionable because that data analysis is based on simplified model assumtions. Despite the fact that $\mathrm{Be}$ has been successfully applied in the fabrication of diodes [11,12], much is still unknown about the structure of this dopant in the SiC lattice.

In this paper, we report on structural and electrical properties of Be implanted SiC. Samples were characterized by secondary ion mass spectrometry (SIMS), Rutherford backscattering spectrometry / channeling (RBS/C), deep level transient spectroscopy (DLTS), resistivity and Hall measurements.

\section{EXPERIMENT}

Epitaxial layers ([0001] orientation, $n$-type, off-axis, thickness: $10 \mu \mathrm{m}$, carrier concentration: $1 \times 10^{16} \mathrm{~cm}^{-3}$ ) grown on $6 \mathrm{H}-\mathrm{SiC}$ substrates as purchased from Cree Research [13] were used as starting material. ${ }^{9} \mathrm{Be}^{+}$was implanted applying energies between 50 and $590 \mathrm{keV}$ (see Table I) in order to obtain a box-shaped profile. Samples were maintained at room temperature (RT), and 
were tilted $7^{\circ}$ with respect to the ion beam to minimize channeling effects during implantation. Ion range and nuclear energy distributions were obtained by Monte Carlo (MC) simulations using the TRIM code (SRIM-98, full cascade) [14]. A mean displacement energy of $25 \mathrm{eV}$ for both $\mathrm{Si}$ and $\mathrm{C}$ atoms was applied. The concentration profile and the nuclear energy density distribution are shown in Fig. 1. The critical energy density for the amorphization of SiC crystal at RT $\left(2 \times 10^{21} \mathrm{keV} / \mathrm{cm}^{3}[15]\right)$ is indicated by the dashed line.

\begin{tabular}{|c|c|}
\hline Ion energy (keV) & Ion fluence $\left(10^{14} \mathrm{~cm}^{-2}\right)$ \\
\hline 50 & 0.61 \\
\hline 75 & 0.62 \\
\hline 100 & 0.63 \\
\hline 130 & 0.84 \\
\hline 170 & 0.74 \\
\hline 210 & 0.85 \\
\hline 260 & 0.80 \\
\hline 320 & 1.00 \\
\hline 400 & 1.03 \\
\hline 490 & 0.94 \\
\hline 590 & 1.52 \\
\hline
\end{tabular}

Table I. Schedule used for Be implantation.

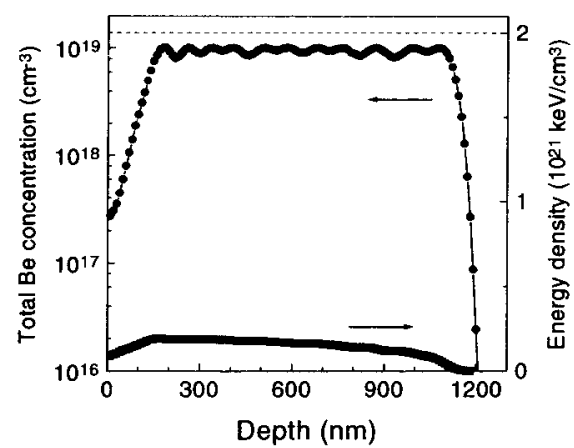

Fig. 1. Total nuclear energy distribution and total dopant concentration for $\mathrm{Be}$ implanted $\mathrm{SiC}$ as calculated using TRIM

To repair the crystal damage and activate the implanted dopant, samples were annealed in flowing argon (Ar) gas (1-2 atm) at temperatures between $1450^{\circ} \mathrm{C}$ and $1700^{\circ} \mathrm{C}$ for 1 min using a rapid thermal annealing (RTA) system. The temperature rise and fall rates were about $50^{\circ} \mathrm{C} / \mathrm{s}$ and $20^{\circ} \mathrm{C} / \mathrm{s}$. Each sample was covered with another $\mathrm{SiC}$ crystal to protect the sample surface from Si dissociation during annealing. Before the electrical measurements, a planar layer of about $0.6 \mu \mathrm{m}$ was removed from the top of the epilayer by applying a combination of ion implantation and wet chemical etching [16,17]. Ohmic contacts were prepared by metal deposition (titanium on the top, nickel on the backside) using an e-beam evaporation system and a post-deposition RTA cycle at $1100^{\circ} \mathrm{C}$ for $5 \mathrm{~min}$ in flowing Ar gas.

To evaluate the thermal stability of the Be profile, SIMS measurements were conducted using a CAMECA ims $4 \mathrm{f}$ instrument with a $14 \mathrm{keV} \mathrm{NO}_{2}^{-}$primary ion beam. The depth conversion was performed by measuring the total crater depth with a surface profiler and assuming a constant sputtering rate during depth profiling. The concentration calibration was performed using a standard sample fabricated by a single energy ${ }^{9} \mathrm{Be}^{+}$implantation. A sensitivity factor was then derived by comparing the area under the SIMS profile obtained from this sample with that one of a profile obtained by a MC simulation.

Resistivity and Hall measurements employing the van der Pauw geometry were performed at RT. To study deep level defects, DLTS measurements were conducted using an equipment described elsewhere [18]. Ionization energies and capture cross-sections were evaluated from the temperature dependence of the emission rates. Finally, damage distributions were determined by $3 \mathrm{MeV}^{4} \mathrm{He}^{+} \mathrm{RBS} / \mathrm{C}$ along the [0001] axis using a scattering angle of $150^{\circ}$. The depth scale given in the RBS spectra below was calculated using the mean energy approximation [19] and the density of the crystalline material $\left(9.66 \times 10^{22} \mathrm{at} / \mathrm{cm}^{3}[15]\right)$. 
SIMS measurements were performed on both the as-implanted and the post-implantation annealed samples to investigate the Be distribution before and after the high temperature treatment. As can be seen in Fig. 2, the near surface tail and the plateau concentration of the asimplanted atom distribution are well reproduced by the MC simulations. However, the slope of the tail towards the substrate is lower compared with the theoretical profile. Channeling effects can be responsible for the observed discrepancy which are not considered in SRIM-98. Since vacancy-type defects far beyond the nuclear energy deposition profile were detected by Positron annihilation spectroscopy [20], defect-enhanced diffusion could be another reason.

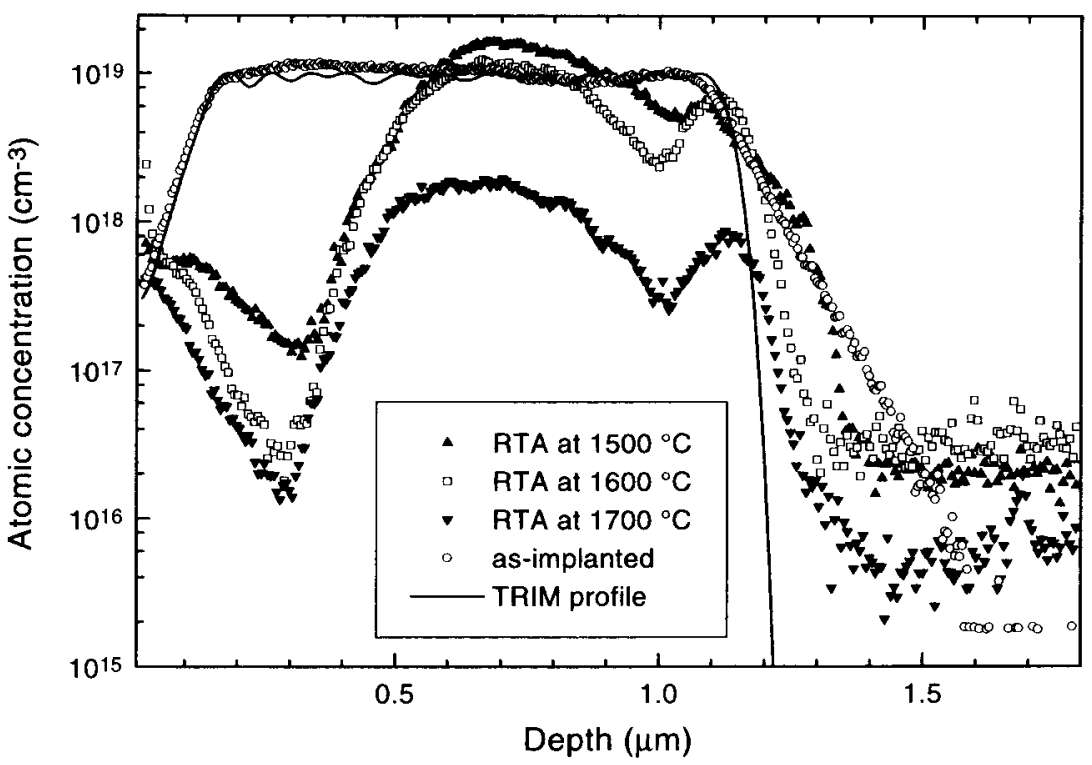

Fig. 2. SIMS ${ }^{9} \mathrm{Be}$ depth profiles in SiC before and after annealing at the temperatures indicated. A simulated depth profile as obtained using TRIM is shown for comparison.

Strong redistributions were found in the annealed samples. The dopant profile is already thermally unstable after a short RTA cycle at $1500^{\circ} \mathrm{C}$. In particular, the heat treatment caused severe depletion of $\mathrm{Be}$ in the surface region up to two orders of magnitude below the asimplanted atom concentration. The integral of the depth profile, which is a measure for the implanted ion fluence, results in a fluence around $30 \%$ lower compared with the as-implanted profile. This indicates out-diffusion of the dopant which increases with increasing temperature, i.e., $43 \%$ and $92 \% \mathrm{Be}$ loss were found at $1600^{\circ} \mathrm{C}$ and $1700^{\circ} \mathrm{C}$, respectively. Implantation induced defects may govern the diffusion process. However, because of the small atomic size of Be, migration via an interstitial mechanism is also anticipated.

Additionally, in-diffusion into the bulk of the epilayer, although less pronounced, was also observed. The higher the anneal temperature the stronger is the redistribution in the tail region. 
Moreover, after RTA at $1500^{\circ} \mathrm{C}$ a peak in the Be profile can be seen at a depth of about $1.1 \mu \mathrm{m}$ which became more pronounced at higher anneal temperatures. It is assumed that $\mathrm{Be}$ atoms were trapped by thermally stable defects formed during the anneal process in this (end-of-range) region.

To remove the Be depleted surface layer, all samples (except the as-implanted specimen) to be examined in the following by RBS and electrical measurements were etched as described above and processed at temperatures $\leq 1600^{\circ} \mathrm{C}$.

Depth (nm)

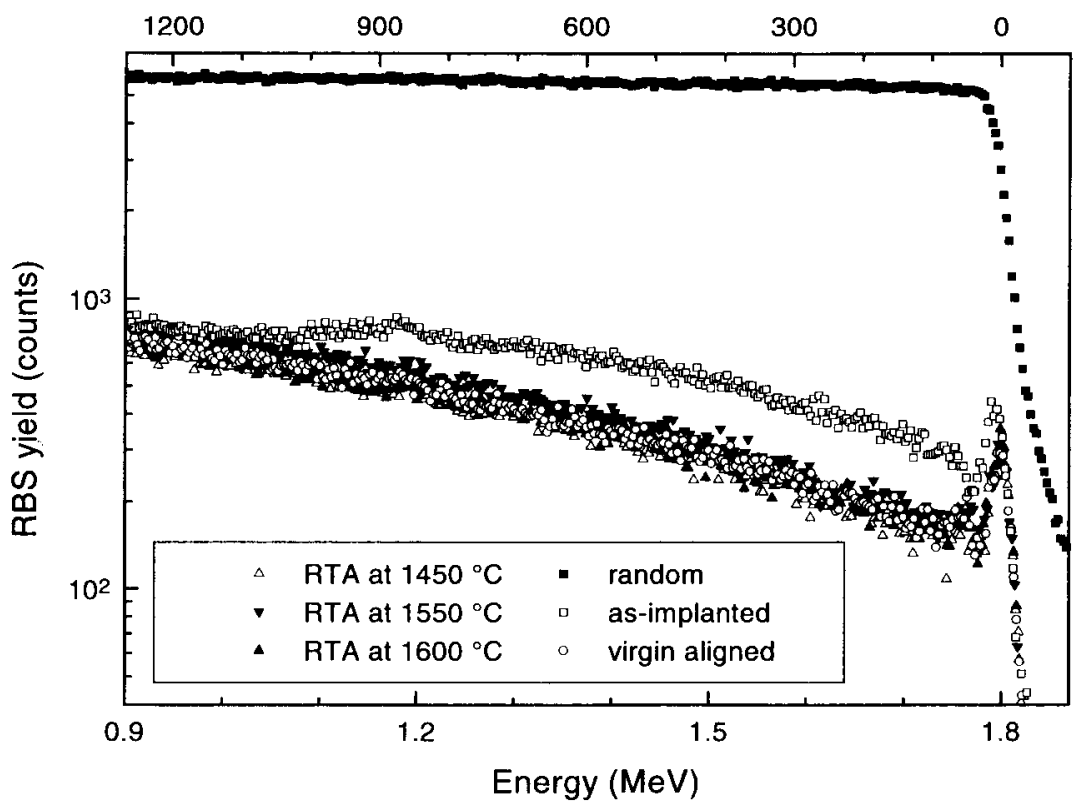

Fig. 3. RBS/C spectra (Si sublattice) of $3 \mathrm{MeV}^{4} \mathrm{He}^{+}$backscattered from Be implanted SiC before and after annealing at the temperatures indicated

To characterize the as-implanted state and to evaluate the recovery of the crystal lattice, RBS/C measurements were performed (see Fig. 3). A random and an aligned spectrum from virgin unimplanted material are also shown for comparison. The scattering yield in the aligned spectrum obtained from the as-implanted sample is far below the yield in the random spectrum. This means that the crystal was not amorphized during implantation, in agreement with the nuclear energy deposition calculated (see Fig. 1). This is a necessary condition for complete annealing of damage induced by ion implantation since defect-free recrystallization of amorphous $\mathrm{SiC}$ is not possible [15]. Further, the yield in the as-implanted sample approaches the yield in the virgin material at about $1.2 \mu \mathrm{m}$, i.e., the damaged region extends up to this depth which is consistent with the calculated energy deposition profile. The peak observed at an energy of $1.18 \mathrm{MeV}$ is due to an oxide layer on the SiC surface which is confirmed by SIMS. 
As can be further seen in Fig. 3, the scattering yield in the aligned spectra from the annealed samples almost coincides with the yield in the aligned spectrum from the virgin sample at all depths indicating a good lattice quality within the sensitivity limit of RBS. Thus, it can be assumed that the crystalline state is well recovered after a RTA cycle at temperatures $\geq 1450^{\circ} \mathrm{C}$. Resistivity and Hall measurements were performed at RT to obtain electrical properties of the doped $\mathrm{SiC}$ layers. For comparison, a virgin unimplanted $n$-type sample was etched and provided with contacts as described above. Although a weak $p$-type conduction was detected in the implanted epilayers (free hole concentrations in the $10^{16} \mathrm{~cm}^{-3}$ range), well reproducible Hall voltages could not be obtained. Obviously, the Hall measurements were strongly affected by the substrate due to insufficient isolation of the $p$-type layer. However, resistivities were found to be about $0.5 \Omega \mathrm{cm}$, i.e., one magnitude lower compared to the virgin sample. Within the limits of these measurements, a dependence on the post-implantation anneal temperature in the range from 1450 to $1600^{\circ} \mathrm{C}$ was not detected.

Finally, a typical DLTS spectrum as obtained after RTA at $1600^{\circ} \mathrm{C}$ is shown in Fig. 4. Four peaks labeled $\mathrm{BE}_{1}, \mathrm{BE}_{2}, \mathrm{BE}_{3}$, and $\mathrm{BE}_{4}$, respectively, were observed in the temperature range from -150 to $+100{ }^{\circ} \mathrm{C}$. Since no DLTS signals corresponding to deep levels were observed in virgin unimplanted samples, all the deep levels were therefore introduced by Be implantation. Ionization energies and capture cross-sections of these levels are given in Table II. For the calculation of the capture cross-sections, these levels were assumed to be electron traps.

Since the free hole concentration of the $p$-type layer produced by Be implantation was found to be of the same magnitude compared to the free electron concentration of the epilayer as stated above, the width of the $p$-type depletion layer is assumed to be comparable to that of the $n$-type one. Thus, the DLTS signals observed may arise from either electron traps at the $n$-side or hole traps at the $p$-side of the $p$ - $n$ junction. The question, whether these levels are donor- or acceptorlike, cannot be answered from the present results but possibly by DLTS measurements on Be implanted $p$-type material provided with Schottky contacts on top of the samples. Further investigations are necessary in order to understand the origin of the deep levels and the structure of the corresponding defects.

\begin{tabular}{|c|c|c|}
\hline Deep level & $\begin{array}{c}\text { Ionization } \\
\text { energy }(\mathrm{eV})\end{array}$ & $\begin{array}{c}\text { Capture cross- } \\
\text { section }\left(\mathrm{cm}^{2}\right)\end{array}$ \\
\hline $\mathrm{BE}_{1}$ & 0.34 & $5 \times 10^{-13}$ \\
\hline $\mathrm{BE}_{2}$ & 0.46 & $5 \times 10^{-14}$ \\
\hline $\mathrm{BE}_{3}$ & 0.52 & $5 \times 10^{-14}$ \\
\hline $\mathrm{BE}_{4}$ & 0.66 & $4 \times 10^{-16}$ \\
\hline
\end{tabular}

Table II. Ionization energies and capture cross-sections of the deep levels as determined from DLTS data

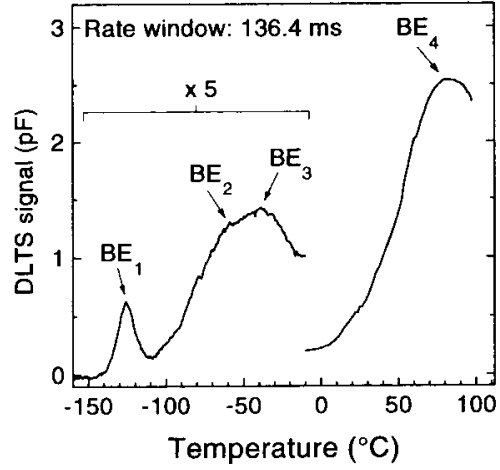

Fig. 4. DLTS spectrum recorded on Be implanted $n$-type $\mathrm{SiC}$ after annealing at $1600^{\circ} \mathrm{C}$ 


\section{CONCLUSIONS}

The doping behaviour of Be implanted into $n$-type $6 \mathrm{H}-\mathrm{SiC}$ epitaxial layers was investigated by SIMS, RBS/C, DLTS, resistivity and Hall measurements. Strong redistributions of the asimplanted Be profiles were found after RTA at temperatures $\geq 1500^{\circ} \mathrm{C}$. In particular, Be diffused towards the surface on a higher level than into the epilayer. As a consequence, severe $\mathrm{Be}$ depletion in the surface region occured. Moreover, it was shown by RBS/C that the crystalline state is well recovered after a short RTA cycle at $1450^{\circ} \mathrm{C}$. However, four deep levels labeled $\mathrm{BE}_{1}, \mathrm{BE}_{2}, \mathrm{BE}_{3}$, and $\mathrm{BE}_{4}$ were observed by DLTS which were generated by Be implantation. The energy position of these levels as well as the nature of the corresponding defects is still an open question.

\section{ACKNOWLEDGMENTS}

We thank Y. Ishida for the help during the Hall measurements. One of the authors (T.H.) gratefully acknowledges the support of this work by Science and Technology Agency of Japan.

\section{REFERENCES}

1. T. Troffer, M. Schadt, T. Frank, H. Itoh, G. Pensl, J. Heindl, H.P. Strunk, M. Maier, phys. stat. sol. (a) 162, 277 (1997).

2. M.V. Rao, J.A. Gardner, P.H. Chi, O.W. Holland, G. Kelner, J. Kretchmer and M. Ghezzo, J. Appl. Phys. 81(10), 6635 (1997).

3. T. Henkel, Y. Tanaka, N. Kobayashi, I. Koutzarov, H. Okumura, S. Yoshida and T. Ohshima, Mat. Res. Soc. Symp. Proc. 512, 163 (1998).

4. M. Gong, S. Fung, C.D. Beling, G. Brauer, H. Wirth and W. Skorupa, J. Appl. Phys. 85(1) 105 (1998).

5. T. Troffer, G. Pensl, A. Schöner, A. Henry, C. Hallin, O. Kordina, E. Janzen, Mater. Sci. Forum 264-268, 557 (1998).

6. G.L. Harris, Properties of Silicon Carbide, (INSPEC, London, 1995), pp. 153.

7. A.A. Kalnin, Y.M. Tairov and D.A. Yaskov, Sov. Phys. - Solid State 8(3), 755 (1966).

8. Y.P. Maslakovets, E.N. Mokhov, Y.A. Vodakov and G.A. Lomakina, Sov. Phys, - Solid State 10(3), 634 (1968).

9. O.J. Marsh and H.L. Dunlap, Rad. Eff. 6, 301 (1970).

10. P.G. Baranov, Mater. Sci. Forum 264-268, 581 (1998).

11. N. Ramungul, Y. Zheng, R. Patel, V. Khemka and T.P. Chow, Mater. Sci. Forum 264-268, 1049 (1998).

12. N. Ramungul, V. Khemka, Y. Zheng, R. Patel and T.P. Chow, IEEE Trans. Electron Devices 46(3), 465 (1999).

13. Cree Research, Inc., 4600 Silicon Drive, Durham, NC 27703

14. J.F. Ziegler, J.P. Biersack, and U. Littmark, The Stopping and Range of Ions in Solids, (Pergamon, New York, 1985), pp. 1

15. V. Heera, W. Skorupa, Mat. Res. Soc. Symp. Proc. 438, 241 (1997).

16. J.A. Edmond, J.W. Palmour and R.F. Davis, J. Electrochem. Soc. 133(3), 650 (1986).

17. D. Alok and B.J. Baliga, J. Electron. Mater. 24(4), 311 (1995).

18. C.V. Reddy, S. Fung, and C. D. Beling, Rev. Sci. Instrum. 67(1), 257 (1996).

19. W. K. Chu, J. W. Mayer, and M. A. Nicolet, Backscattering Spectrometry, (Academic, New York, 1978), pp. 64.

20. H. Wirth, W. Anwand, G. Brauer, M. Voelskow, D. Panknin, W. Skorupa and P.G. Coleman, Mater. Sci. Forum 264-268, 729 (1998). 